\title{
Matar al otro en el teatro argentino del siglo XXI. Tras las pistas de Rodrigo Cuesta en la escena del crimen
}

\section{Lourdes Magalí Pereyra Fedele}

Universidad Nacional de Córdoba, Argentina

lumagateatro@gmail.com

Fecha de recepción: 28/03/2018. Fecha de aceptación: 26/04/2018.

\begin{abstract}
Resumen
La desconfianza invade al lector de Mataral otro, obra del escritor Rodrigo Cuesta. De la discontinuidad de la intriga, emerge una lectura de insistente sospecha, arraigada en una diestra manipulación del lenguaje que, disfrazado de irrisorio juego inocente, secuestra hasta el final toda posibilidad de reordenamiento de las partes. Con la interpretación de los acontecimientos restringida, se somete a los lectores a un proceso indagatorio doble. Mientras resuelve los fragmentos escénicos dispersos, yuxtapuestos y repetitivos, los equívocos, vacilaciones e incomunicación dialógica entre los personajes, el lector debe seleccionar y acumular información capaz de solucionar el dilema intra-diegético, asumiendo un rol indagatorio, en una especie de teatro detectivesco, que parece desear distanciarse del teatro de posvanguardia argentino. Inserta en una trilogía que explora formas de la desconfianza en las relaciones humanas, es posible rastrear en la obra analizada, factores que revelan la sustancia del terror y el desprecio hacia el sujeto otro, extraño y siniestro. Un régimen socioeconómico que anula la experiencia erótica del $Y o$, en un predominio de Ares -y no de Eros, como indica el pensador Byung Chul-Han-, que aniquila al Otro, destruyendo simultáneamente al Uno. En una depresiva sociedad narcisista, temor y odio establecen el eje de este endeble edificio, que amenaza desmoronarse trágica y vertiginosamente.
\end{abstract}

\section{Killing the Other in 21st Century Argentine Theatre. Following Rodrigo Cuesta's Trail on the Crime Scene}

\begin{abstract}
Distrust invades the reader of Matar al Otro (Killing the Other), written by Rodrigo Cuesta. From the intrigue's discontinuity, an insistently suspicious reading emerges, as a result of a smart manipulation of language that, disguised as a laughable and innocent game, kidnaps any possibility of rearranging of the parts until the end. Unable to fully interpret the events, readers are subjected to a process of double inquiry.
\end{abstract}

Palabras clave

Cuesta; desconfianza; teatro detectivesco; Eros;

Otros/Uno;

Matar al Otro
Keywords

Rodrigo Cuesta; Distrust; Detective Theater:

Eros; Other/One 
While trying to put together the dispersed, superposed and repetitive fragments of the scene and to deal with the ambiguities, hesitations and dialogic isolation between the characters, the readers must gather and select information that can help them to solve the quandary, assuming an investigatory role, in a sort of police or "detective theater", which seems to distance itself from most Argentine post-avant garde theater.

Inserted in a trilogy that explores forms of distrust in human relations, the analyzed work displays factors that reveal the substance of terror and scorn towards the strange and sinister Other. A socioeconomic regime that annuls the erotic experience of the One (oneself), expressing a predominance of Ares -and not of Eros, as Byung ChulHan points out- and that annihilates the Other, while simultaneously destroying the One. In a depressive narcissistic society, fear and hate establish the axis of this weak tower, which threats to crumble tragically and vertiginously.

\section{Introducción. Rodrigo Cuesta, un dramaturgo extemporáneo}

Habiendo recorrido un camino de lectura específico, a través de diversas obras teatrales, durante el seminario "Dramaturgias Argentinas del Siglo XXI", dictado por la Dra. Laura Fobbio en 2017, por la Universidad Nacional de Córdoba, descubrimos la obra Mataral otro, de Rodrigo Cuesta, cuyos procedimientos y elementos particulares han obligado a conducir nuestro análisis personal por un sendero curiosamente ajeno al trazado en el estudio de las producciones argentinas del siglo XXI.

Si bien es cierto que la apertura a una multiplicidad de poéticas desde los años sesenta configura el marco creativo que dispone la coexistencia de realizaciones escritas y teatrales heterogéneas, no es menos cierto que puede percibirse una predilección por ciertos aspectos de la creación, por ejemplo, la propensión a deponer el texto escrito por la acción escénica aquí y ahora y a las posibilidades infinitas que las dramaturgias escénicas (actorales, escenográficas, luminotécnicas, musicales, de vestuario, etc.) proponen. Sin embargo, la lectura de las formas que estructuran el drama que examinaremos en su estado literario evidencia que los constructos metodológicos de aquellas dramaturgias, propias de la modernidad tardía y de las posvanguardias, no parecen estar operando de igual modo aquí.

Por lo tanto, a continuación esperamos demostrar que Matar al otro, última pieza de la trilogía de La desconfianza de Rodrigo Cuesta, no participa de los rasgos característicos de las producciones consideradas posdramáticas e, inclusive, pone en cuestión aspectos de la dramaturgia nacional de posvanguardia, teorizados y formulados por hacedores argentinos, como Emilio García Wehbi y Alejandro Tantanián, encarando problemáticas insertas en la familia y la sociedad moderna, para lo que retomaremos brevemente consideraciones sobre Modernidad Liquida de Zygmunt Bauman. Desde otra perspectiva, y guiados por la mirada alerta de Byung Chul-Han, podremos reconocer en la obra, formas de complejizar -e impedir- la experiencia erótica.

$\mathrm{Al}$ indicar que en esta obra de principios de siglo XXI no se aplican ciertas operaciones renovadoras del arte teatral de mediados del siglo XX, podremos situar al autor en cuestión en posición de hacedor extemporáneo, insólito, imprevisto, inadecuado a lo que el teatro contemporáneo renovador ha preferido durante casi medio siglo, en espacios de indagación de la ruptura. Pero rescatemos una última acepción del calificativo con el que designamos al autor en cuestión asociada a la noción de anticipado: el anuncio de un probable nuevo posicionamiento respecto de la literatura teatral, que retorna perspicaz a la instancia escrita como fundamento autosuficiente, valioso en sí, más allá de la representación escénica. Una tendencia renovadora (tal vez solo referente a este caso en particular, tal vez generalizable) que, sin embargo, 
aún no estamos en condiciones de anunciar, por ser muy pronto, pero que parece si no intentar abandonar, por lo menos alterar los parámetros performativos posmodernos que trajo fines de siglo XX, que perviven en la primera década del siglo XXI.

\section{Planteo Primero. La anti-posvanguardia de Rodrigo Cuesta}

Comencemos recuperando ciertas nociones asociadas al binomio teatro-política, propuestas por Emilio García Wehbi, en el texto "La poética del disenso. Manifiesto para mí mismo" (2012).

En principio, es viable observar que opera en Mataral otro aquello que García Wehbi designa como "imbricación de una forma y contenido nuevos que descoloquen las presunciones del público", y "que afirman su carácter abierto e incomodidad" (2012: 21), ya que la denuncia de la corrupción en el proceder humano (crimen, traición, venganza, encubrimientos, mentiras, tortura y abuso, racismo, tráfico de órganos) no se encuentra sosegada por el discurso políticamente correcto de la temática, complaciente de obvias expectativas, sino desestabilizando con la "interrupción poética de las reglas de la cultura y la ley" (2012: 21), tal como indica García Wehbi. Ahora bien, en la obra de Cuesta prolifera cierta supremacía del texto escrito, cuya jerarquía, García Webhi insiste, hay que abolir en pos de un "teatro de texturas, no de textos" (2012: 23). En Matar al otro, los vacíos que la subjetividad del espectador debe completar no son generados por delimitaciones indefinidas del lenguaje, sino al contrario, por un medido ejercicio lógico del lenguaje puesto a disposición de aquellos vacíos, apelando a las capacidades asociativas y cognitivas del espectador. Aquí domina el texto y la palabra no es potencial imagen metafórica escenificada (como pretende García Wehbi), sino un saber válido en sí mismo, que aporta en sí toda la información requerida y que el oído atento del espectador debe saber descifrar. Un universo codificado total, inspeccionable, que Cuesta instala en un departamento de ciudad, presentado en una escena teatral equivalente a una escena de crimen, digna de peritajes e investigación. Las pruebas a ocultar (la pastafrola como evidencia, la calvicie del Toro cubierta por una peluca) y los interrogantes a desocultar (quién asesinó a la mujer disfrazada de enfermera que yace en el baño, y a las otras seis mujeres del edificio; quién asesinó a Tamara; quién es Teresita y qué intenciones tiene; de quién son las cenizas de la urna; qué secretos oculta cada personaje) son elementos contundentes planteados explícitamente en el discurso textual.

Admitimos reconocer cierto uso de procedimiento antimimético (que García Wehbi reclama para un teatro actual). No obstante, debemos observar que no hay resistencia a la interpretación, sino un ritmo que aletarga la asociación de los sentidos puestos en juego, no para anularlos, sino para postergarlos, en una estrategia discursiva típica del género policial clásico. El sentido último no puede quedar definitivamente expulsado, sino temporalmente en suspenso, pues hay un caso dilemático que resolver. De la misma manera, es cierto que reconocemos discontinuidad, pero no asociada a una multiplicidad de códigos. Tampoco hay en la obra de Cuesta rasgos de utopía postantropocéntrica, puesto que se representa atendiendo a la significación fundada en la información ofrecida por los personajes y por las circunstancias y, en esto, también se opone a lo que propone García Wehbi.

Por otro lado, la incomodidad generada no es sensorial, sino cognitiva, dirigida a la inteligencia racional (no creativa o emocional), lo que implica intentar develar qué ocurre mientras se intenta develar cómo se manifiesta discursivamente lo que ocurre. Apela a un trabajo intelectivo doble y simultáneo, el reordenamiento del rompecabezas. Nuevamente, esto se opone a lo que García Wehbi rescata de Rancière: en Matar al otro, la obra es el "maestro omnisapiente" que construye un público 
(lector-espectador) no emancipado, sometido a la duda, a la desconfianza de la escena, al ansia de verdad. En definitiva, aquí no podemos reconocer el disenso que pretende García Wehbi. Al final de la obra, habrá una sola lectura posible (o muy pocas en su defecto), pues no opera sobre la subjetivación del público, tornándolo activo, sino antes bien, sometiéndolo a un lugar de pasividad desconcertante, en donde cualquier interpretación diferente del resultado de esta ecuación es errónea, destinada a morir. El lector-espectador de Matar al otro no puede ser activo, pues resuelve conforme el dramaturgo de a poco, va concediendo piezas-pistas del rompecabezas, en una especie de intento de homicidio intelectivo del lector. No se construye aquí un lector desgarrado, sino un confundido y desconfiado lector, de fruncido entrecejo.

Si bien en principio se conserva el decoro aristotélico respecto de la obscenidad, situando la muerte en el relato, fuera de escena (Toro: "Fue el pastor...me hizo ver todo... Se le fue la mano. (...) La hizo mierda"; 2013: 89), o sustrayéndola de la visión del lector-espectador (Toro: "hay una chica, en la casa, en el baño, muerta, dentro de la bañera"; 2013: 75). Hacia el final lo obsceno copa la escena (la muerte de Tomás, el Toro y Teresita, y la aparición en escena del órgano recién extirpado de la mujer que nunca llega a verse muerta). Entre esas dos maneras de situarse frente a lo obsceno, intermedia una escena de quiebre: el relato de Teresita en "escena 12 " se manifiesta simultáneo en acción, sin abandonar su carácter narrativo. De pronto, texto, narración y acción, avanzan comunicadas sin atropellarse, para rasgar el velo que conserva oculto lo obsceno y desembocar, así, en la desinhibida exposición final. En definitiva, lo observado revela un salto de lo aristotélico a una forma de escenificar, que no coincide con lo que García Wehbi desearía para la escena, esto es, evitar la obscenidad. Existe una voluntad críptica, no hermética en la dialéctica con el público, tal como se plantea en "Poéticas del disenso (...)", pero con la diferencia de que no se intenta aquí, librar al público a su propia subjetividad, sino acercarlo (cercarlo) al sentido oculto (ocultado) intencionalmente por el formato dramatúrgico. Matar al otro es una experiencia visitable, apática, muy distinta de lo que podría esperar García Wehbi.

Por otro lado, y retomando la noción de dramaturgia de Joseph Danan (a su vez, recuperada del concepto de Jean-Marie Piemme), que la define como "todo elemento teatral elaborado en la dialéctica entre un objeto que se ofrece a la vista y una mirada que pueda captarlo, que instala el orden de sentido, de la significación", observamos que en la obra analizada es esa instancia dialéctica la que se pone en crisis. Dice Danan, "el sentido estará constantemente amenazado ante su posible explosión, atomización, dispersión o diáspora" (2012: 13). Retengamos a nuestros fines, la idea de un sentido disperso (y no el resto de las posibilidades), pues con claridad el conflicto expuesto es unívoco y marcha a un desenlace explicativo, a través de las pruebas instaladas en el transcurso del relato. Pero es la dispersión irregular de esos datos los que dificultan el acceso a la comprensión y el descubrimiento de la verdad. Elementos suministrados en fragmentos, de modo reiterativo o contradictorio. El juego con la "organización de la acción", noción de Jean-Luc Nancy retomada por Joseph Danan (2012: 14), se presenta como el auténtico conflicto teatral, mientras que el crimen a resolver adquiere carácter de dilema.

Aunque no es pertinente aquí establecer la dicotomía presentar-representar como dualismo funcional a nuestro análisis -pues se trata sin duda de una representación-, ocurre que la mimesis representacional, si la entendemos, como explica Danan: "acción ejecutada en escena que representa una acción que se supone ha sucedido en el mundo" (2012: 15), que es puesta en crisis. El orden surrealista de las acciones de Matar al otro nunca podría corresponder con el orden cronológico realista, naturalista del mundo empírico. El efecto ilusorio de superposiciones, repeticiones de escenas y diálogos análogos, retrocesos en el tiempo, indican ruptura del procedimiento mimético de la representación escénica convencional. Pero, ¿son esos rasgos, indicios 
suficientes para inscribir a la obra dentro del híbrido corpus de la era posvanguardista? ¿O podemos pensar que las diferentes formas de plantear la misma escena (por ejemplo, los ingresos de Teresita en escena) adquieren el parecido de una fórmula matemática, en que el orden de los factores no altera el producto? Si apreciamos esta posibilidad interpretativa como válida, la "escena 12", que "convertida" en "Escena 1 " introduce en la obra una especie de mise en abyme, aunque sea un característico recurso empleado desde André Gide por las vanguardias artísticas, no representa una prueba suficiente para considerar que la obra participe del campo que engloba la posvanguardia; en principio, porque es una técnica que proviene de la heráldica practicada desde la antigüedad, pudiendo con ello responder a otra clase de recurso discursivo; pero, sobre todo, porque, en esta ocasión, su aplicación tiene el fin pragmático de retomar un caso planteado en términos policiales, al modo de racconto retrospectivo que reúne las piezas dispersas y resuelve el enigma.

Si pensamos en la producción de Alejandro Tantanian como referencia del hacer dramatúrgico de posvanguardia argentino, seguimos encontrando diferencias significativas. Podemos, por ejemplo, considerar que aquí el artificio dramatúrgico no es puesto en evidencia como en la obra de Tantanian y que no es la palabra la que genera imágenes, sino que la palabra en sí es la que se torna sospechosa y merece ser indagada; asimismo, que el público en Matar al otro es testigo, pero no interpelado (como se puede detectar, por caso, en Muñequita o juremos con gloria morir). Tampoco podemos decir que operen mecanismos como la autorreferencia o la autoreflexividad, propias de las producciones posmodernas argentinas.

De la misma manera, si atendemos a las representaciones de la muerte, no son comparables a imágenes recurrentes de las dramaturgias actuales, asociadas a aquello que Adriana Musitano denomina cambios tanatomórficos -tales como la peste, la contaminación y la putrefacción- en este caso, sino al contrario. Observamos un afán por mostrar la muerte intacta e in situ, sin pudrición, inclusive el órgano extirpado de modo profesional es cuidadosamente conservado para su reutilización.

\section{Planteo Segundo. Formas del drama para matar al otro}

Como dijimos antes, podemos considerar que se pone en crisis tanto la relación dialéctica entre el objeto mostrado y el sujeto que observa, como la relación mimética representacional a nivel diegético. Esta última, causante del primer eje problematizado.

Si tenemos en cuenta consideraciones de Beatriz Trastoy respecto de operaciones del teatro de posvanguardia, debemos reconocer que, si bien Matar al otro "no busca ser espejo escénico, duplicación de similares experiencias existenciales que, por su atribuida validez universal, aseguran los procesos de identificación emocional del espectador" (2012: 233), es cierto que tampoco intenta dicho objetivo poniendo en crisis "la noción aristotélica de representación como instancia fundacional del teatro, es decir, como reproducción de personas y acciones, remitiendo a otra cosa diferente de sí."(2012: 232). La representación aristotélica entendida de ese modo sigue funcionando, pero aplicada a un relato cuya estructura responde al mecanismo de solución de intriga, clásica del género policial. Es allí donde la mimesis sufre modificaciones, sin que por eso deje de operar. Se trata de la mimesis de un proceso indagatorio, que revela cierta asociación de este texto teatral en el campo del género detectivesco.

En este sentido, recuperamos una imagen con la que Ricardo Piglia define al escritor, en una analogía que ya es clásica. En su relación con el profesional de la crítica literaria, el escritor asume el rol de un criminal, especie de delincuente que "borra sus huellas y cifra sus crímenes perseguido por el crítico" (1991: 20), convirtiendo la 
estructura del relato en investigación. Desde nuestra posición, diremos que la tradición de la novela policial clásica ha engendrado esquemas narrativos que se reproducen en la esencia de la literatura argentina. Es así que en Mataral otro, las marcas de esta herencia, son incuestionables. Por supuesto que no estamos encasillando categóricamente la obra de Cuesta, ni afiliándola -todavía- al género policial o detectivesco. Decimos que diversos elementos podrían considerarse partícipes de la tradición que mencionamos, pero desde la transgresión y la periferia, no solo porque, en principio, no podemos perder de vista que es un texto escrito para la representación teatral, sino porque, además, reúne atributos de diversas variedades del policial, tornándose indefinible. Indefinible porque si bien el delito en nuestra obra pretende ser asumido como un problema matemático, como crimen sin criminal, aspecto tradicional del policial inglés, éste no sublima las relaciones sociales que encuadran la trama, en un entorno en que el dinero "sostiene la moral y legisla la ley" (Piglia, 1992: 56), que es típico del thriller norteamericano, pero también del policial negro argentino desde Roberto Arlt, que acarrea a todos los personajes hacia la corrupción y la exaltación violenta. Así es que escuchamos las sirenas anunciándose a lo lejos, rodeando la manzana, la presencia del Estado en la institución policial, sospechosa y ausente a un tiempo. Aquí, Mataral otro ya podría integrar una especie de teatro de la serie negra argentina. Como negar que su estructura se asemeja a la literatura policial, descripta por Daniel Link como "relato sobre el Crimen y la Verdad", que "articula de manera espectacular las categorías de conflicto y enigma" (1992: 6).

Sin embargo, como indicamos, su esencia es teatral. Asistimos a la hamletiana escena de reconstrucción de un acto criminal, en que los personajes representan de modo inesperado y sin acuerdo previo, lo que la detective Teresita relata: una escena de teatro dentro del teatro, sin contratos. La verosimilitud al borde del abismo se ofrece a un género -el policial- que nunca alcanzará su forma fija.

El rol detectivesco en la fábula lo asume Teresita. Sus acciones y discursos, la reconstrucción de los hechos en una especie de informe oficial, la investigación previa, el camuflaje para insertarse en el ámbito de los supuestos delincuentes, reúnen las características básicas del estereotipo. Sin embargo, recordemos que la atención se focaliza en la desconfianza total que alcanza a todos los personajes; por lo tanto, su presencia y sus intenciones (la venganza) la convierten en un personaje que es tanto el de una detective amateur, como el de una potencial criminal. Y lo será.

La parodia del género policial es en sí un recurso habitual del género. La autorreferencia burlesca implícita en el cuerpo del texto analizado, se amplía en el matiz ridículo y desopilante de las escenas, en los gestos patéticos y las apariencias grotescas de los involucrados en delitos graves. Pero, además de esto, se quebranta una ley fundamental del género detectivesco: "Debe ser realista en lo que concierne a personajes, ambientación y atmósfera", y "no se deben ocultar al lector las claves" (Chandler, 1992: 41); es decir, existe un principio de honestidad con el lector en su proceso deductivo, que la obra desconoce. Se dan una serie de accidentes (una peluca que se cae, por ejemplo) y confesiones directas (Teresita admite introducir veneno en la pastafrola) o indirectas (Tania revela que ha hecho "cosas malas"). El discurso disloca la intriga, la rodea, divagando con elementos en una lógica algo caótica.

Indica Jaime Rest, "Así nace la novela policial, como respuesta a una necesidad indudable de la vida moderna: la necesidad de escapar de las cosas previstas, uniformes, cotidianas" (1974: 39). Hágase extensiva esta reflexión a la búsqueda que emprende Matar al otro. Algo en esa búsqueda se distancia de las formas actuales del hacer teatral en Argentina, en que la deconstrucción de la imagen, por momentos -no en todos los casos- se torna un simple abuso desconcertante, una fiebre muda y exagerada que, poco a poco, por insistencia, en algún punto se ha esclerosado. Este echar mano de 
los recursos literarios clásicos, una especie de retorno renovado a un formato literario -el policial o detectivesco-, que en los últimos años ha dejado apagar su gloria, viene a intentar reencontrarse con otras caras del teatro.

Pero esta especie de fábula de cuarto cerrado se encuadra en un marco axiológico que hace del género detectivesco un recurso más para poder acercarse a un espectro de reflexión que excede el marco de la convención genérica para indagar lo humano desde una perspectiva integral, que reunirá un acento en el aspecto, no solo policial y legal, sino en el encuadre psicológico, sociológico y filosófico, en torno al eje violencia, que intentaremos deconstruir en adelante, y que recuerda las reflexiones de Ricardo Piglia respecto de la naturaleza monstruosa y enigmática del otro, que acecha desde afuera.

La violencia es, según Jorge Dubatti (2017: 9), un rasgo típico del teatro de posvanguardia. En especial para la dramaturgia argentina posdictatorial, que rastrea la problemática social de los "efectos disolutorios que generan los crímenes no castigados" (Musitano, 2016: 255). La violencia surca de principio a fin la obra que analizamos, a través de gestos y diálogos, pero también se manifiesta aquí en la acción de venganza por mano propia (venganza del homicidio de Tamara o del ataque a la madre de Tomás). La efectiva aplicación del castigo sitúa al factor violencia en otro plano: el enfrentamiento mano a mano entre los personajes.

A la manifestación explícita de la violencia en relación con la figura del otro, que trataremos más adelante, sumamos un modo de la violencia, latiendo subyacente en la dimensión discursiva del entramado textual. Un tratamiento de la disposición textual, que altera el proceso mimético, desplazando el foco de atención del argumento al discurso. Así, la intriga no solo se instala en la incógnita del desenlace y destino de los sujetos, sino sobre todo, en el interrogante permanente acerca del la forma. Dado que la desconfianza es eje medular del drama que revisamos, el relato se construye instalando la desconfianza en el proceso mismo de la mímesis, imitando todas las realidades posibles, y engendrando la duda en el lector, y en el espectador (puesto que así se supone, será llevada a escena). Podríamos decir que este artificio con los signos es propio del hacer teatral de posvanguardia; hemos visto, sin embargo, que con ello no apunta a generar interpretaciones libres o ambiguas, sino una guía basada en el arte de narrar, de teatrar textualmente, podríamos inferir. Pero el formato que opera aquí, dispone confusamente una serie de indicios de compleja coherencia, y la guía enreda el sentido, planta pistas falsas. La intriga no es solo lo que se cuenta, sino cómo se lo cuenta, y en esto demora el lector, no por la metáfora vanguardista que implosiona al signo y favorece su deconstrucción, sino por la duda, inseguridad de acertijo y trabalenguas pretencioso, que deriva inevitablemente en la desconfianza del lector hacia el relato teatral.

La sombra de la inseguridad se proyecta en la construcción de las figuras de personaje y fábula. Respecto de los personajes, estos son caracterizados por aspectos que enmascaran la verdad en apariencias ambiguas: pelucas, disfraces, la protuberancia del Toro, que es una media, un tumor o aceite de avión, los desmayos e inmediatas recomposiciones, actos de beneficencia, aparente inocencia, la mujer en su oficio de prostituta disfrazada de enfermera, el cura del que nadie desconfiaría.

En cuanto a la inseguridad inserta en el plano de la fábula, es útil retomar una idea de Marco Antonio de la Parra, desarrollada en su artículo "La palabra en el abismo" (2010: 19), donde indica que el arte mayor del dramaturgo es "mantener un naufragio en escena el tiempo suficiente sin que naufrague el interés del público". Es así que Matar al otro instala al lector-espectador frente al vacío interpretativo, una latencia dubitante que amarra ante la intriga, no la que se manifiesta en su argumento como 
explicamos antes, a nivel del enunciado, sino en la intrigante, inaprensible forma de exponer la enunciación (sucesión de acciones, entradas y salidas de personajes y sus identidades). La confusión retiene el interés, hasta que, al reconstruir el formato discursivo, se establece frente a la obra un pacto de lectura apropiado, acorde a la verosimilitud interna, autónoma de la secuencia, asumiendo así una posición develadora, una especie de proceso indagatorio atento a descifrar la escena como escena de un crimen.

El rol detectivesco del lector vincula la información en apariencia racional, que se escapa por los intersticios del surrealismo imperante. Capturar datos exactos con los cuales poder reconstruir, no solo el orden de los acontecimientos, sino además la diégesis de la escena (dilucidar, por ejemplo, qué personaje ingresó en qué momento en determinada escena). Es la razón por la que la fórmula matemática que sustenta la obra funciona, pues pone en juego las operaciones típicas del relato policial clásico, en el tiempo y espacio particularísimo del teatro, y las consecuentes limitaciones de la escenificación aquí y ahora. Para evadir la revelación de las causas de una serie de crímenes, elementos del surrealismo postergarán hasta el final la solución de los problemas planteados. El equívoco y fracaso en la intercomunicación, la superposición reiterada de escenas idénticas, fragmentos que se repiten con alguna pieza diferente y reveladora a descubrir, agregándose a ocultamientos, mentiras y secretos, versiones diferentes del mismo hecho. La sensación de una circularidad infinita en la secuenciación de las acciones cesa en el absurdo trágico de una muerte múltiple, revelando que múltiples son también las formas de matar al otro. Cada uno vuelve efectivo un homicidio (por venganza u oficio, como el de traficante de órganos) y, como veremos en adelante, incluso Tania morirá en cierto modo, dado que es ella la supuesta séptima mujer en la lista (lugar ocupado por la prostituta disfrazada de enfermera, que cierra la ecuación). En Mataral otro, un sujeto otro asesinado no siempre implicará un sujeto otro sobreviviente. Con su muerte, la prostituta debería poder salvar a dos personas, al potencial receptor del órgano y a Tania, pero veremos que, en este último caso, la situación resulta adversa.

Cada actor asume estatuto de un personaje único, prefijado y estable, que se sostiene en escena. No hay crisis de personaje en el sentido del teatro posmoderno, pero sí opera una especie de reconfiguración conforme avanza la acción, asociada a un aspecto cognitivo: el secreto reiterado. Poco a poco, reconstruimos mentalmente las identidades ocultas. La ambigüedad resulta de las mentiras detrás de las cuales se ocultan los personajes, no por fractura o mutación. Simulan, actúan, inventan, se disfrazan. Apariencias y acciones asociadas a secretos: introducir veneno en un alimento que se ofrece con amabilidad, escaparse de la cárcel disfrazado de mujer, inventar la propia muerte, introducir cenizas ajenas en la urna de un familiar, usar peluca sobre una cabeza calva para disimular la participación en pandillas delictivas, esconderse en la oscuridad -Tomás, Teresa-, ocultar un cadáver en el baño, encubrir el delito de un amigo -colectivero-, y las intenciones siniestras ocultas, por ejemplo, detrás de la apariencia inocente del oficio de Tamara o tras el contrato de servicio de una trabajadora sexual.

El ocultamiento como conflicto nodal sostiene el modo de interacción entre los personajes (dificultad dialógica) y es, además, la estrategia discursiva aprovechada para generar desconcierto en el lector (dificultad dialéctica).

El método de ocultamiento como medio para matar al otro pareciera ser el verdadero crimen puesto en cuestión: la confianza traicionada por la mentira (que puede llevar a la muerte), que paralelamente funciona con el juego del lenguaje al que el lector se somete, quien sucesivamente es traicionado por una serie de ocultamientos, los cuales, al revelarse, complican aún más la comprensión de la situación, el acceso a la verdad. 
"Matar al otro" aquí es alejar la verdad, generar desconfianza que torne sospechoso lo que acontece y cómo se presenta lo que acontece. Como indica Spregelburd. el procedimiento apunta a "ese sentido que está detrás, y que necesariamente debe permanecer velado" (2015: 60), para que sirva de soporte de las formas.

\section{Planteo Tercero. Formas de la Otredad en Matar al otro}

Aún después de la muerte, el cuerpo inerte que yace en la tina continúa siendo útil, reutilizable. El órgano extraído del cuerpo sin vida es lo último que aparece en escena. Extirpado, robado, sale de la escena del crimen para entrar en el círculo del mercado de tráfico de órganos, imprimiéndole continuidad, pues aún es capaz de generar vida. Sin embargo, es resultado de un acto criminal, opuesto a valores éticos y morales instalados en el imaginario colectivo y en el ámbito legal, que llevará corrupción a la sociedad, pero que es expectativa de sobrevida a un cuerpo otro que lo requiera. La paradoja de matar a un sujeto otro para dar vida a alguien más, un nuevo otro, genera una ambigüedad que desemboca en nuevas formas de desconfianza entre los individuos. Desconfianza acerca del origen de las cosas, que se manifiesta de diversas maneras: de dónde viene el órgano, de dónde la pastafrola, de dónde vienen el Toro y Teresita, que intenciones traen, etc. Esta desconfianza deriva en la duda. La incertidumbre acerca de cómo actuar en una situación desconocida o inesperada, provocará diálogos como el siguiente: Tania: ¿Qué estás pensando?/ Tomás: Si le abro o no le abro/ (...)/ Tania: Es que vos siempre pensás, pensás y nunca hacés...". (Cuesta, 2013: 69).

Pensar, nunca hacer. Es importante indicar que en la obra de Cuesta no reconocemos constante despliegue de sucesos concatenados, consecuencia directa del acto realizado, sino más bien superposición y sumatoria: dispuestos unos sobre otros, los acontecimientos y los sujetos involucrados, se pliegan cada uno a su turno, envolviendo al otro, acumulando información.

Este plegarse superpuesto es consecuencia de la violencia como operación inexorable. Retomemos un instante, el pensamiento barthesiano según el cual, todo individuo ejerce violencia siempre (opta, discrimina, descarta). Confiar en otro y permitir que ingrese al espacio privado, apropiado e íntimo, que atraviese el umbral que separa de lo desconocido (aquello que permanece afuera, al otro lado de la puerta) transforma la representación que del sujeto se tenía mientras este permanecía afuera. Una vez que el sujeto desconocido ha atravesado el umbral ocurren dos fenómenos. Uno, se deja de ejercer la violencia del aislamiento sobre ese otro, ahora incluido. Dos, fluye otro tipo de violencia, pues ese otro que ingresa, en este caso, es desconocido y peligroso, no confiable. Teresita asume la condición de desconocido, al igual que el Toro, en la representación mental y psicológica de Tania, quien expresa: “¿Y este quién es?”; “(...) para mí, mi hermano está muerto” (2013: 73-74). Ese otro que es incorporado, pero con cautela y precaución, instala con su presencia lo siniestro, que se sitúa bajo ese umbral y, en ese vaivén dubitante, se instala la inseguridad. La puerta es bisagra, es el paso que, aceptando (incluyendo) o negando (excluyendo) a la otredad, abre el camino a la desconfianza. Así lo expresa Tania: "Una es tonta, confía, abre la puerta de su casa a una completa desconocida, para... ayudar..." (2013: 87).

Pero las acciones, ingresos en escena y diálogos se repiten casi idénticos, generando cuadros cual si fueran falsificaciones, que de a poco dejan ver pinceladas gruesas algo grotescas, dudosas, para dirigir la mirada hacia la versión original de los acontecimientos, al final de la obra. Precisamente en esos cuadros que rebobinan y continúan tendiéndose gradualmente sobre ellos mismos, que simulan no dejar avanzar la intriga, se refuerza la mirada sobre la desconfianza, la serie de posibilidades infinitas que emana el otro. 
Cuando los elementos del cuadro ubican su lugar, y todo es calma y orden, la puerta del departamento es reescrita, resignificada por el azar de la tragedia: el destino en la obra, tuerce el curso de las acciones planificadas en torno a la muerte. El espanto se instala cuando el razonamiento del sujeto conciente, pensante y libre, interviene en la realidad para tornarla monstruosa, naturalizando el horror. El ser humano es capaz de adaptar las situaciones, mediante la improvisación. Así Tania, descoloca el orden matemático de las apariciones y crímenes, para imponer su propia lógica sencilla, incuestionable ("Siete más tres, diez"), y triunfar sobre la adversidad, calculando con cuidado de cirujano. Lo siniestro a medio camino, confluye en el umbral, llegando desde afuera, escapando desde el interior del espacio.

Nos propusimos explicar por qué la obra de Cuesta se aparta de nociones y técnicas características del teatro de posvanguardia, pero en adelante reflexionaremos sobre posibles motivaciones intelectuales, que la propia selección y disposición del material teatral puede revelarnos. Nos referimos a formaciones discursivas del entramado textual, capaces de manifestar adhesiones ideológicas, cuya latencia inevitable subyace en el trasfondo político de todo hacer artístico.

Nos detendremos un instante en esta reflexión de Walter Benjamín, acerca de la relación entre lo público y lo privado:

Vivir en una casa de cristal es virtud revolucionaria por excelencia. Pero es también una embriaguez, un exhibicionismo de carácter moral de los que hoy nos hacen mucha falta. La discreción en cuanto hace a la propia existencia ha pasado de ser una virtud aristocrática, a volverse un asunto de pequeñoburgués arribistas. $(1998,2-3)$

Los acontecimientos se instalan en lo que las acotaciones de Matar al otro, definen como un "barrio raro", "peligroso", en un departamento habitado por un sujeto que "tiene tonada paraguaya, o correntina, o formoseña, o de por ahí". Inicia un proceso de extrañamiento, de estereotipación.

Un sujeto de origen desconocido, que habita un espacio inseguro, en el que las puertas de los departamentos deben asegurarse (" ¿Se puede saber por qué dejaste la puerta abierta? Es decir... ¿Sin llave?", reprende Tania a Tomás)(Cuesta, 2013: 65), al igual que las puertas del edificio (Tania: “¿Qué querés? Ya se quién es, la vi. ¿Qué necesitás? No tenemos nada...digo, no queremos nada acá. ¿Quién te abrió abajo?"/ Teresita: "Estaba abierto") (Cuesta, 2013: 69). En este entorno, no es lógico el ingreso imprevisto de alguien (Tania: "Es él que llegó de sorpresa") (Cuesta, 2013: 83), y no es conveniente que alguien salga al exterior (Tania: "Tomás no sale. Tiene miedo"/ Teresita: “¿Por cómo está todo? Este barrio... ¿mucha violencia? ¿De qué tenés miedo?") (Cuesta, 2013: 82).

Por lo que podemos ver, los dueños de casa, Tania y Tomás, construyen las barreras necesarias para evitar ser observados o intervenidos por el afuera. La máscara del decoro y de la seguridad sirve a Tania para autoconfigurarse como sujeto confiable y confiado ("Qué fácil que es meterse en la vida de los otros ¿no?...Una es tonta, confía...") (Cuesta, 2013: 87), enfrentada a la embestida violenta de lo ajeno, desconocido e inseguro (expresa Teresita: “Abrí hijo de puta, abríl", "Sí sé que estás ahí. Abrí..." y “¿Me pueden abrir?" (Cuesta, 2013: 69), “¿Puedo pasar?" (Cuesta, 2013: 78), "Se escucha todo de afuera ¿Saben?" (Cuesta, 2013: 80)). La pareja Tania-Tomás, constituye una célula pequeñoburguesa que, como indica Benjamin, vive en la discreción del anti-exhibicionismo. No mostrar ( $\mathrm{se}$ ) esconde un misterio siniestro, que detona en la conexión con extraños. 
La presencia del otro extraño, que no pertenece al hogar, no es la peor amenaza. La obra instala el extrañamiento en el núcleo familiar. Una familia que crea una imagen socialmente aceptable, pero que se asegura de no ser vista ni oída, puertas adentro: mientras Tomás intenta convencer a Tania de permanecer juntos, en la casa ("que construimos del corazón...un lugar de amor... de cariño", dice Tomás) (Cuesta, 2013: 85), Teresita revelará en él, la paranoia del culpable, que vigila luego de cometer su crimen ("desde la ventana ve algo... ¿A mi? Yo estoy abajo y lo observo. Me escondo", explica Teresita) (Cuesta, 2013: 90).

Las personas extrañas son la víctima (mujer muerta en la tina, atraída hacia ese espacio privado para ocupar el rol de víctima central) y la vengadora (la girlscout que ingresa a ese espacio privado con la voluntad de convertirse en victimaria). Ambas ajenas a la relación de familiaridad que se establece entre los otros personajes. Sin embargo, el extrañamiento se disemina en el orden general de las interrelaciones. La duda en el desconocimiento del otro es experimentada por todos. El distanciamiento y la inseguridad de no poder dilucidar la identidad y motivaciones de los sujetos, adquieren carácter de extraños, y son esas máscaras cotidianas expuestas incluso en el círculo cerrado de la familiaridad (generada por parentesco o amistad), las que la obra exhibe y problematiza.

Teresita se arrepiente luego de concretar su venganza, y su condición de persona ajena a la relación previamente establecida entre el resto de los personajes, se diluye. Su máscara de extraña cae, mientras el resto de los personajes refuerzan los hilos de las suyas. Cae y devela su condición humana, el arrepentimiento en apariencia más afectuoso y cercano que las actitudes de los otros entre sí (Teresita: “(...) Toro...Yo no quería esto... ¡Toro! ¡No te mueras!”) (Cuesta, 2013: 88). Esta actitud se reproduce entre los extraños, y será Tania la que se exprese afectivamente, con cierta empatía hacia la desconocida Teresita (Tania interrogando al Toro: “ ¿Vos le mataste la hermana a esta pobre chica?") (Cuesta, 2013: 89).

Aquí, la relación entre extraños se desplaza del orden de lo desconocido, hacia cierto grado de familiaridad, lo que refuerza aún más la duda.

El Otro, el extraño no solo es el sujeto desconocido, sino aquel conocido porconocer, e inclusive lo es el sujeto en sí mismo; es decir aquello por develar del Uno, la compleja naturaleza compleja que lo habita, y su potencialidad violenta, vengativa, rencorosa. Todos los personajes actúan agresivamente, pero la duda sobre su accionar los lleva al arrepentimiento, real o aparente. El Toro intenta justificarse y negar su participación en el ataque de los skinhead; Tomás secuestra y asesina, pero insiste en su miedo, su inocencia; Tamara logra su venganza, para inmediatamente arrepentirse. Y, finalmente, Tania confiesa en desesperación: "Basta. Me tengo que ir (...) Hice cosas horribles, cosas que nunca tendría que haber hecho. Por venganza por plata por maldad...". (Cuesta, 2013: 92) En su caso, Tania debe abandonar el espacio que asocia con sus fechorías, el espacio doméstico, propio y privado. Allí resguarda el secreto que insiste en develar Teresita, la desconocida que llega para recordarles que es en ese ámbito donde habita la desconfianza (Teresita: "un secreto, todos tenemos un muerto encerrado en el baño") (Cuesta, 2013: 88).

Una dualidad en los sujetos que lleva a Tania al cálculo insensible. Hacia el final, las acotaciones son elocuentes al respecto, pues Tania se arrepiente, no de sus acciones, sino de partir sin antes dejar una pista policial que desvíe la atención lejos de ella.

La ley que rige este hogar, su ecónomos, configura interrelaciones atravesadas por un régimen competitivo, trasfondo capitalista que percibimos inserto en el devenir que estructura los hechos, donde son humanos lo que se selecciona y descarta, en la 
vorágine salvaje de la supervivencia, la superioridad de poder, en este caso, no solo representado por la posibilidad de seguir existiendo, sino por la de adquirir rédito económico, especie de utilidades que genera el secreto y la mentira, explícitamente en los siguientes fragmentos:

Toro: “(...) el pastor me hizo ver todo...Yo necesitaba esa plata”. (2013: 89)

Toro: “Matala Tomás. iNecesito plata Tania!” (2013: 92)

Tania (acerca de Toro): “Le robó el bolso nomás" (2013: 92)

Tania: “(...) cosas que nunca tendría que haber hecho, por plata, por maldad...”

(2013: 92)

Pero los secretos no solo sirven de sustento del afán de lucro. Para poder ingresar a este espacio regido por la avaricia y la ambición, Teresita aprovecha los recursos del discurso monetario. Dice Teresita: "Al final pura pérdida el negocio"; "las scouts no manejamos plata" y "Es la voluntad" (Cuesta, 2013: 84) y, en el siguiente parlamento, con el que se autoconfigura como sujeto benefactor de confianza, debido a su carácter caritativo y no lucrativo, al mismo tiempo que ofrece el alimento mortal: "Me dicen Teresita de toda la vida. Como la madre Teresa de Calcuta. ¿Está rica?" (Cuesta, 2013: 84)

El inconveniente se instala puertas adentro de un espacio reducido y no en espacios vacios, públicos y multitudinarios. Sin embargo, la ley que rige la vida privada y pública de análogo modo. Una lógica silenciosa, cómplice de secretos macabros y obscenos, reproducida en distintas clases de abuso de poder: la joven Tamara asesinada por el pastor de una iglesia, las partes involucradas en el delito de trafico de órganos, la cárcel y sus códigos intra-carcelarios, la policía rodeando el edificio, Toro en calidad de prófugo de la justicia, el grupo skinhead y su ajusticiamiento nazi de raza superior, la justicia por mano propia. Una ley económica que analizaremos a continuación, desde la mirada Byung-Chul Han.

\section{Los unos y los otros, desde la perspectiva de Byung-Chul Han}

Caminando por una ciudad como la que Byung Chul Han (2014) imagina seríamos capaces de reconocer lo que define como predominio de la positividad en una sociedad de lo igual, exenta de experiencia erótica que ofrece la negatividad atópica del Otro. De pronto, Eros solo aparece en escena, en la cercanía del Otro, enfatizándolo sin régimen del $Y o$, sustraído al lenguaje y carente de lugar. Pero, cuando progresivamente la exterioridad negativa y asimétrica del otro se pierde en la necesidad urgente de positividad, inicia lo que el pensador coreano indica como "proceso dramático", ${ }^{1}$ en que la alteridad del otro se suspende, en busca de la diferencia.

Desde esta perspectiva, Matar al otro ofrece señales: una mujer, prostituta de profesión, yace en una tina, sustraída, atópica. Está muerta y no ha desempeñado su rol sexual. Encarna la cancelación de la experiencia erótica, imposibilitada por el crimen, el régimen de uso. Destruyendo su negatividad, queda igualada en su identidad, a todas las latinas muertas en tinas, a toda enfermera asesinada. Resta la carne. Cuerpo humano, órgano extirpado. El crimen es igualación y deriva en el proceso dramático de la desaparición progresiva de los otros. Una potencial confusión se sortea matando a todos, nivelados víctimas y victimarios. Paso a paso, y a prisa, se desencadena la positividad trágica de la igualación final. La relación amorosa imposible es detectada por Tania, desde el inicio:

No me toques. Me das asco (...) y yo... siento... no puedo hacer nada...hasta acá llegué Tomás. No doy más. (2013: 67)
1. Han expresa "el hecho de que el otro desaparezca es un proceso dramático" (2014: 10). Podríamos sugerir aquí, que Ego y Alter-Ego son anulados en pos de figuras agonistas y antagonistas, posible motor fundamental de la construcción del entramado teatral, y nos aventuramos a pensar también, posible clave para diferenciar la producción del texto literario de narración ficcional, de la produc ción de una dramaturgia textual. 


\section{(...) para mí, mi hermano está muerto (2013: 74) \\ (...) una es tonta, confía, abre la puerta de su casa a una completa desconocida, para...ayudar... (2013: 87)}

La sociedad construye sujetos narcisistas, depresivos y no delimitados, que proyectan su Yo sobre el mundo, en la confirmación del uno por el otro, quien "queda degradado a la condición del espejo del uno" (Han, 2014: 12). Matar al otro es un laberinto de espejos, de imágenes insertas en su propia reiteración abismada, en la indefinición entre el origen y las copias. Espejo es la prostituta disfrazada de enfermera y las seis mujeres asesinadas; espejo es la urna falsa, con cenizas de una desconocida ocupando el espacio del hermano supuestamente muerto; en espejo se reproducen las escenas, acciones y discursos que reaparecen acentuando la intriga. Un laberinto agobia en el desconcierto de la salida, el agotamiento. Pero una conformación espejada de sus paredes altera la percepción de la propia realidad, en el multiplicado retorno de figuras que son familiares pero cuya integridad despierta sospechas, una minuciosa desconfianza, el terror de avanzar hacia la salida. Eros es don del otro, voluntad de vaciamiento de sí mismo. En la obra, el exceso de reconocimiento del yo fomenta la percepción siniestra del otro, que irrumpe desde afuera, para quebrantar la monotonía: es esa joven girlscout, situada en el umbral de la puerta, de misteriosas intenciones.

Así, Tania solo podrá abandonar la escena, descubrir la salida del laberinto traidor, cuando la amenaza del otro por fin desaparece, en la síntesis del proceso dramático. Los desmayos de Tania gestualizan la depresión del éxito: "Tania shockeada mira lo sucedido, se desmaya"/ "Tania se incorpora y mira los cuerpos regados por el piso" (93), indican las acotaciones. Allí, encuentra el sí mismo en todas partes, pero sin poder deleitarse, a causa de un narcisismo contrario al amor propio.

Es cuando el desastre (catástrofe, Apocalipsis) de la irrupción del Otro llega a su fin. Inicia un reinado opuesto a Eros, sometido al régimen de uso de la sociedad de consumo, que aspira a eliminar la alteridad atópica a favor de diferencias heterotópicas, materializando el orden instalado: la muerta en la bañera es el doble que Tania precisa para escapar indemne. Tania es actor manipulador y víctima manipulada, explotador-explotado, sometida a una libertad neoliberal, cuyo imperativo violenta al sujeto a rendir más, a sacar provecho en la auto-explotación. La enfermera aumentará su productividad y partirá de la escena creyéndose a salvo, acarreando consigo la metáfora latente de su sumisión narcisista: el órgano extirpado de la falsa Tania, su doble personal asesinado, productivo y útil. Chul-Han expresa que el capitalismo es solamente endeudador, genera insolvencia que no reconoce religión, culpa, ni perdón, abandonando al sujeto a sí mismo.

La anulación del ejercicio de poder sobre el otro, el fracaso, es la única posibilidad de acercamiento a aquel. Cercanía es tensión y herida, situada en el futuro debido a la imprevisibilidad del "tiempo del otro" (Han, 28). Tania requiere perder a los otros, pero con ellos, ella misma es extraviada: su identidad resta tendida en la tina, en el cuerpo mutilado de una desconocida, un otro que la transforma en la negatividad de la atopía. Tania, por su parte, quedará condenada a habitar una positividad permanente, perdida de todos, en condición de ocultamiento prófugo.

Tania lleva consigo un fragmento de su yo muerto, cuyo destino será la comercialización. En la "cosificación económica del otro" (Han, 2014: 30), Tania lo pierde todo, sacrificando hasta lo último que cree pertenecerle, precisamente el extracto de un otro. Solo Eros puede interrumpir esa relación de cambio capitalista, puesto que la asimetría y alteridad del otro, no es alcanzable, ni poseíble, no se consume ni intercambia. Pero en la obra, el otro es órganos para vender, es objeto de venganza. Otro es lo imposible de amar, lo asexuado (Tania y Tomas, Tomas y la prostituta, el Toro y Tamara). Otro 
es lo que se puede tocar, quebrantando todo erotismo (Teresita toca el pecho artificial del Toro) o aniquilándolo (el pastor que asesina a Tamara). Finalmente, predomina la mera vida capitalista contra la muerte, pérdida absoluta. Tania "permanece en sí misma dentro de la muerte" (Han, 2014: 34), celebra su falsa muerte para continuar esclava de su tarea acumulativa, pero desde ahora ya no estará viva ni muerta del todo; en oposición a la girlscout, quien "va a la muerte consigo misma", pues es capaz de arriesgar su propia vida, ya que posee "capacidad de muerte" (Han, 2014: 34).

Han expresa la idea de que el espíritu se demora en la devastación, para definir su carácter absoluto (2013: 38).

Tania sale de escena huyendo, en pos de supervivencia de su mera vida abandona impávida la escena de muerte. Se va sin incluir en sí la negatividad de los otros en ese estado de muerte. Tania se arrepiente antes de salir, pero no es el espíritu lo que la detiene, un razonamiento práctico que garantiza la continuidad de su actividad productiva económica, logos sin Eros: la prueba falsa en las manos de sus muertos, en la puerta de su casa, el cálculo inserto en la escena del crimen, el órgano extirpado en la "bolsita transparente" (Cuesta, 2013: 93).

El "capitalismo obsceno" (Han, 2014: 37) y la información adulterada que "ejerce un efecto deformativo", sumado al predominio de ruido, o a su ausencia temporaria. No existe el silencio-pensamiento: sirenas acercándose que aceleran acciones, diálogos oídos desde afuera, expresiones confundiéndose en la proximidad: Tomás: "Pero si ni-la-garré”. Tania: “¿Silvina Garré?” (Cuesta, 2013: 80); Teresita: "Todos tenemos un muerto adoptado... ¡Encerrado!" (Cuesta, 2013: 83); “... podría estar adoptada... ¡Operada!” (Cuesta, 2013: 85).

Han retoma interpretaciones de Hegel respecto de lo absoluto, en que el amor es "retorno reconciliado desde su otro a sí mismo" (2014: 38). Tania eleva un Logos sin Eros que la conduce a la aporía respecto de sí misma. La primacía del otro (poder del Eros) implica renunciar a la conciencia de sí mismo, la capacidad de morir. Perderse y morir en el don del otro devuelve al sí mismo reconciliado, autoposeso. Pero en la obra de Cuesta predomina la violencia de Ares, el paranoico afán de dominio concluye sustrayendo a los personajes de sí mismos, cínicos, perdidos tras las máscaras y disfraces con las que acallan sus traiciones y ocultan sus semblantes. Porque la experiencia erótica se alcanza en la muerte de la identidad imaginaria del yo, del orden simbólico que construye. Tania enfatiza la producción de sí misma, su propia esclavitud. Dice Chul Han: "Lo que induce al esclavo futuro a someterse al otro, es el miedo a la muerte" (2014: 34).

Es así como inicia la obra. Tania se condena a la auto-explotación acuciada por una sociedad que escapa a la muerte y al erotismo. Tras el desastre, Tania es una superviviente -no muerta, pero sin vivacidad- una especie de zombi (figura que ha recuperado un espacio encumbrado entre los personajes de la producción ficcional actual) que desfallece y se reincorpora contantemente, al igual que el resto de los personajes, cuyas muertes fingidas y vidas robadas, profanan el erotismo. Así ocurre con el pastor que asesina a Tamara, en un proceso de desritualización, desacralización pornográfica, que arrastra con violencia la expectativa y distancia erótica del Toro respecto de la joven.

La prostituta, como indicamos, encarna en su muerte la imposibilidad erótica, pero es su atuendo, el disfraz de enfermera, el objeto sexual que lleva bordada la marca ilusoria de la frustración, equivalente a la decepción actual que fomenta el exceso de información y las altas expectativas inalcanzables. La coacción, en oposición a la quietud y la demora contemplativa, arrastra a Tania a un desenlace semejante a la sexualidad pornográfica: una escena del uno, la habituación del amor del uno por el 
otro uno, un narcisismo autoerótico sin conmoción ni distancia. Tania solo llevará consigo un fragmento de carne de aquella prostituta que ocupará en adelante, el lugar de su muerte.

No es el "impulso de Eros" (Han, 2014: 65) lo que predomina en Matar al otro, sino un "impulso de Ares", propio de una sociedad neoliberal que reprime la posibilidad de un nosotros y de la negatividad de la fantasía, de la ruptura. Aquel que espera por entrar en escena, situado en el umbral de la puerta, en una de esas "zonas llenas de misterios y enigmas, donde comienza el otro atópico" (Han, 2014: 64),

En el imposible nosotros hay carencias. La ausencia de demora, la insistencia de los personajes que vociferan ansiosos necesidades de modo "urgente de urgencia" (Cuesta, 2013: 83, 92). A cada instante falta la negatividad que ofrece la ruptura, por lo que el estado de las cosas sigue existiendo igual a sí mismo. Solo hacia el final, todos los personajes, a excepción de Tania, quebrantan el estado de las cosas, pero sin abandonar un accionar dominado por la ira, una valentía (thymos) sin amor (eros), que los lleva a desconocer y desaparecer al otro (proceso dramático). En la protagonista rige un logos degenerado por la ausencia de Eros, es decir, un "solo el cálculo es llevado por datos" (Han, 2014: 74).

Tania no se incorpora al acontecimiento que engendra lo distinto. Ella prefiere habitar lo igual, pues, como entiende Han, "al pensamiento calculador, guiado por los datos, le falta la resistencia del otro atópico" (Han, 2014: 72). Cuando los otros caen muertos, la enfermera desfallece (conmoción narcisista quizá), pero al reincorporarse, adviene la responsabilidad del trabajo. Ya sin el otro atópico, y la seducción con la que este "desata en el pensamiento un deseo erótico" (Han, 2013: 72), desaparece. Actúa/trabaja con frío orden de un pensamiento aferrado a lo seguro, para no transitar lo no calculable, lo no recorrido (lo impronunciable de las pérdidas que acaba de sufrir, la situación traumática y sus consecuencias).

\section{El enigma $T / 7$}

Ya que, según Han, el pensamiento sin Eros es meramente repetitivo y aditivo, la organización para la escena del crimen y la extirpación del órgano se llevan a cabo a partir de información positiva y científica, aditiva y detectiva.

Allí prospera nuestra lectura. Un caso detectivesco en el planteo general de la obra, que se nutre en la exposición de hipótesis surgidas desde perspectivas diferentes, en torno a cuestiones diversas: el asesinato de Tamara, el ataque a la madre de Tomás, la chica muerta en la tina. El juego retórico con el signo lingüístico $T$, se asocia a ese equívoco. La $T$ predomina como inicial de los nombres de pila, y en el fraseo del acertijo.

En el juego de palabras, en apariencia inocente, se pone en jaque el punto de vista, activando sentidos en torno a la cifra. Descifrar el enigma $T / 7$ es clave para el lector. Al traspasar el umbral que aísla de lo externo, Tania dejará de ser Tania. En la séptima mujer asesinada, anónima por cierto, Tania abandonará su nombre, su identidad y su pasado y deposita para la policía una mirada de lo ocurrido en la escena del crimen, un orden de los factores que altera el resultado, pero ofrece una solución que podría ser suficiente para la policía. "Siete argentinas bien latinas, se lastiman en la tina" (Cuesta, 2013: 68).

Con la séptima mujer se cierre el círculo de crímenes. Se ha cumplido con la cantidad planificada por algún supuesto asesino, quien, diestro en su tarea, no podría darse el lujo de un imprevisto. El exceso, tres cadáveres sobrantes, cuyos nombres o 
pseudónimo inician con $T$, no puede ser interpretado como evento azaroso no calculado previamente, por lo que con una simple suma, inscripta en la escena del crimen, se resuelve el defasaje que traería más problemas a la policía fiscal. Eso en cuanto al número. Pero la " $T$ es una incógnita lanzada al espectador-lector, como elemento de distracción, inserto en un marco poco confiable de planteo de un problema. Un elemento que sostiene la relación de inseguridad y desconfianza, que pretende engañar y plantar pistas falsas para el espectador-lector.

\section{Teatro, el otro}

Matar al otro concibe críticamente el infierno de lo igual, no solo en su contenido temático, como pudimos observar, sino además en su estructura formal. Esto último se encamina por dos vías: una radica en un paralelismo discursivo que se despliega intermitente, acumulando información que complejiza la comprensión a cada instante. La apariencia surrealista ${ }^{2}$ de este método, ese relato distorsionado de escenas sumatorias que se presentan y se re-presentan casi análogas, es precisamente la segunda vía formal con la que la obra convoca y resiste el reinado de lo igual. Cuesta arriesga, retrocede a buscar la primacía textual, para aventurarse a abrir una visión novedosa en el actual campo dramatúrgico, hoy estancado en cierta conformista positividad posmoderna. La obra se entrega al cálculo y la prolijidad racionada en la deconstrucción deliberada del lenguaje, exenta de aquel azar performático, que, delicioso en sus inicios, hoy se revuelve sobre sí, licuando la escena actual en un sinsabor reconocido. Narcisista, el teatro posmoderno es hoy espejo de espejos. Su éxito es la caducidad, por lo que, podemos decir, ha triunfado. En oposición, hay en esta audaz especie de teatro policial de Cuesta, una voluntad renovadora.

La condición de existencia del teatro es el otro. El teatro nace y muere en el otro. El otro dispone su emergencia. El teatro es de naturaleza fractaria (hacia su interior la realidad es idéntica): la esencia del drama es (en) el Otro. Que el otro desaparezca es un proceso dramático, indica Han. Pues en teatro, el Otro ocurre siempre, aun desapareciendo: la ficción construye al desaparecido, al drama. Sin embargo, en el mundo no ficcional, cuando el régimen del $Y o$, absoluto y depresivo, ocasiona el terrorismo, el otro desaparecido es irreconstruible, y resta solo la deconstrucción imaginaria de los procesos de memoria. En oposición, "La atopía del otro se muestra como la utopía del Eros" (Han, 2014: 14).

Neoliberalismo, "desinhibidos impulsos del yo y el rendimiento" (Han, 2014: 43) derivan en una agonía del Eros, que acarrea una crisis actual del arte, un posmoderno todo igualado, que en su excesivo deslimitar desfallece en los síntomas de la depresión narcisista, para reincorporarse de inmediato siendo esclavo del hacer que ofrece mayor acumulación de capital simbólico, y que aborrece concluir por un mero vivir igual a sí mismo, acumulando desproporcionadamente para superproducir sinsentido ${ }^{3}$. Ambiciosa de excesos, la forma teatral actual es puesta en discusión con sagacidad en Matar al otro.

\section{Conclusión}

Nos hemos acercado a una manera de escribir teatro a principios del siglo XXI, que al parecer comienza a distanciarse de las formas de interconexión generalizada de posvanguardia, para redescubrir nuevas maneras de desconexión, a través de una dramaturgia textual que no pretende desestabilizar fronteras, sino recurrir a clásicas convenciones teatrales (observamos un caso semejante en la obra Simulacro y fin, del joven escritor cordobés Maximiliano Gallo).
2. Han expresa que Eros es manifestación revolucionaria, elemento clave del movimiento surrealista: “En los surrealistas el Eros es el medio de una revolución poética del lenguaje y de la existencia" (2014:70)
3. Al respecto expresa Byung Chul-Han:"Las informaciones como positividades no cambian ni anuncian nada. Carecen por completo de consecuencias" (2014:76). 
Una desconexión como eje de contenidos, pues como indica Zygmunt Bauman, en la modernidad los límites de la comunidad se han reducido a espacios cada vez más estrechos, debido a una "política del miedo cotidiano" (2010: 102), que se instala en la cotidianeidad construida por el imaginario ficticio de la obra que analizamos. En ese marco de inseguridad, expresa Bauman (retomando a Richard Sennet), opera la civilidad, habilidades empleadas en el encuentro inevitable entre extraños en la vida pública, una máscara que se ofrece al otro para no importunar con la propia presencia. El encuentro entre extraños en Matar al otro, un acontecimiento sin pasado ni futuro (2010: 103), según Bauman debiera ser evitable. Sin embargo es aquí, en el marco de la vida clausurada de un espacio íntimo privado, en el que no solo los desconocidos, sino sobre todo los personajes que poseen lazos de familiaridad, poco a poco dejan caer sus máscaras. En este caso, estas máscaras no han sido construidas con el fin de armonizar la interrelación entre extraños, sino para ocultar siniestros objetivos. En definitiva, el encuentro aquí también es inevitable, pues es la sed de venganza, la pulsión de muerte y de lucro, los que los moviliza. Cuando la máscara de un sujeto Otro no extraño cae, el efecto de extrañamiento, el distanciamiento desconcertante, producido a nivel privado, cercano, se torna intolerable, en el reconocimiento de una ley ventajista, competitiva y traicionera, inserta en el núcleo familiar, que reproduce la norma que rige las relaciones humanas a nivel comunitario capitalista, que sostiene la estructura del hogar moderno burgués, marcado de antemano por la imposibilidad de ser construido como un lugar de amor.

Matar al Otro es matar la posibilidad de saberse a Uno mismo. No hay posibilidad de acceso o conocimiento del uno, sin el conocimiento del otro. Ahora bien, cuando se presume que este (el uno y su integridad) está determinado por el material, la posesión de una existencia material (que no es ni el uno ni el otro, sino la materia en sí misma -objeto de uso, intercambiables, bienes que ofrecen el confort cotidiano, tecnología, bienes muebles, inmuebles, tierras, bienes virtuales de valor financiero, etc.-) se impone como clave de progreso del uno, un sujeto otro devenido estorbo será potencial imposibilidad de lo material en el Uno, una amenaza a exterminar. 


\section{Bibliografía}

" Bauman, Z. (2010). “Cuando los extraños se encuentran con extraños" de "Espacio/Tiempo" en Modernidad Líquida. Buenos Aires: Fondo de Cultura Económica.

» Boido, J. (2000) “Sangre sabia”, en Radar libros, Página 12, edición digital. Buenos Aires.

"Cuesta, R. (2013). La desconfianza 3. Matar al otro, en Confluencias. Dramaturgias serranas. Encuentro de jóvenes dramaturgos Jorge Díaz. Buenos Aires: INT.

"Danan, J. (2012). Qué es la dramaturgia y otros ensayos. Trad. De Víctor Viviescas. México: Paso de Gato.

»Dubatti, J. (2017). "vanguardia/post-vanguardia en la historia del teatro: relación por campos procedimentales y modos de lectura" en revista Arteescena, №3, Valparaíso: Universidad de Playa Ancha.

»Fobbio, L. (2010). “Alejandro Tantanian y el nombre de las cosas”, en telondefondo, Revista de Teoría y Critica Teatral, año VI, № 11, julio. Disponible en: $<$ http://www.telondefondo.org/numeros-anteriores/numero11/articulo/254/ alejandro-tantanian-y-el-nombre-de-las-cosas.html>.

" García Wehbi, E. (2012). "La poética del disenso. Manifiesto para mí mismo", en Botella en un mensaje. Córdoba: Alción-Ediciones DocumentA/Escénicas, pp. 19-31.

» Han, B-H. (2014). La agonía del Eros. Barcelona: Herder.

»Lafforgue, J. y Rivera J. B. (1995) Asesinos de papel. Ensayos sobre narrativa policial. Buenos Aires: Colihue.

» Link, D. (1992) “Prólogo. El silencioso juego de los cautos”; PIGLIA, R.“Cuentos de la serie negra"; Chandler R. "Verosimilitud y género", en LINK, D. El juego de los cautos. Buenos Aires: La Marca.

» Musitano, A. (2014). "Las poéticas de lo cadavérico. Memoria ritual del arte y rituales satánicos. Teatro y plástica de la Argentina de finales del siglo XX”, en Miriam Pino et al, Lenguaje de la memoria l. Córdoba: Narvaja.

»Musitano, A. (2015-2016). El tratamiento de la muerte en dramaturgos argentinos, 1980-2000, en Dramateatro Revista Digital. Córdoba: Universidad Nacional de Córdoba.

» Pavis, P. (2016). “Apropiación”, “Escritor de escenario”, “Escritura dramática”, "Escritura performativa", en Diccionario de la performance y del teatro contemporáneo. México: Paso de Gato.

»Piglia, R. (1990). Crítica y ficción. Buenos Aires: Siglo XX.

»Piglia, R. (1991). “La lectura de la ficción”, en Suplemento Clarín Cultura, Buenos Aires.

» Rest, J. (1974). “Diagnóstico de la novela policial”. Buenos Aires: Crisis, XV.

»Sanchis Sinisterra J., De la Parra, M. A. (2010). El arte del monólogo. La palabra en el abismo. México: Paso de Gato.

"Spregelburd, R. (2015). “Procedimientos”, en Detrás de escena. Buenos Aires: Excursiones. 
»Trastoy, B. (2012). “Traducir la Muerte para Pensar el Arte: apuntes sobre la escena posdramática", Revista Brasileira de Estudos da Presença, Porto Alegre, Universidade Federal do Rio Grande do Sul, v. 2, n. 1, p. 231-248, jan./jun. 2012; 231-248, ISSN 2237-266o. Disponible en <www.seer.ufrgs.br/presenca>.

» Todorov, T. (1992). “Tipología del relato policial” en Link, D. El juego de los cautos. Buenos Aires: La Marca.

"Williams, R. "El surrealismo: La última instancia de la inteligencia europea (1929)". 1998, 2002, en Agrupación mayo, edición digital Easy PDF Copyright (c) Visage Software. Disponible en <http://www.mercaba.org/SANLUIS/Filosofia/autores/Contempor\%C3\%A1nea/Teor\%C3\%ADa\%20Cr\%C3\%ADtica\%20 -\%20Francfort/Benjamin/El\%20surrealismo.pdf>. 